\title{
Perancangan Aplikasi Buku Pintar Ibu dan Bayi Berbasis Android (Studi Kasus : Puskesmas Janti Kota Malang)
}

\author{
Listanto Tri Utomo ${ }^{1}$, Farid Wahyudi ${ }^{2}$ \\ ${ }^{1}$ Informatika, Fakultas Sains dan Teknologi, Universitas Islam Raden Rahmat Malang, JL. Raya \\ Mojosari No.2, Kepanjen, Malang \\ ${ }^{2}$ Sistem Informasi, Fakultas Sains dan Teknologi, Universitas Islam Raden Rahmat Malang, JL. Raya \\ Mojosari No.2, Kepanjen, Malang
}

\begin{tabular}{|c|c|}
\hline Info Artikel & ABSTRAK \\
\hline $\begin{array}{l}\text { Riwayat Artikel } \\
\text { Diterima: 07-10-2020 } \\
\text { Direvisi: 09-11-2020 } \\
\text { Disetujui: 22-12-2020 } \\
\text { Kata Kunci } \\
\text { Perancangan; } \\
\text { Aplikasi; } \\
\text { Buku Pintar Ibu dan Bayi; } \\
\text { Android; } \\
\\
\text { \& Corresponding Author } \\
\text { Listanto Tri Utomo, } \\
\text { Tel. +6285604809564 } \\
\text { listanto.tri @ uniramalang.ac.id }\end{array}$ & $\begin{array}{l}\text { Penelitian ini dilaksanakan karena dilatar belakangi banyaknya } \\
\text { ibu muda yang mempunyai bayi dengan pengetahuan yang } \\
\text { minim tentang bagaimana menjaga Kesehatan bayi. Tujuan } \\
\text { penelitian ini membangun aplikasi buku pintar ibu dan bayi } \\
\text { berbasis android. Untuk pengumpulan data primer, Penelitian } \\
\text { ini mengunakan teknik wawancara, sementara untuk data } \\
\text { skunder, pengumpulan data dilakukan dengan cara } \\
\text { dokumentasi atau riset perpustakaan, internet, serta buku- } \\
\text { buku yang memiliki hubungan dengan penelitian. Metode } \\
\text { pengembangan sistem (SDLC) yang gunakan dalam penelitian } \\
\text { ini adalah mengunakan Metode waterfall yang memiliki } \\
\text { kelebihan yaitu ketika semua sistem dapat didefenisikan secara } \\
\text { utuh dan benar diawal proyek, maka software engineering dapat } \\
\text { berjalan dengan baik tanpa masalah. Dari hasil penelitian yang } \\
\text { telah dilakukan didapatkan sebuah permasalahan yang } \\
\text { menuntut penulis untuk mengembangkan sebuah aplikasi } \\
\text { buku pintar ibu dan bayi berbasis android. Dimana dalam } \\
\text { pengembangan sistem yang telah dilakukan penulis } \\
\text { mengunakan alat bantu pembuatan program yaitu android } \\
\text { studio. Dari aplikasi yang telah dibuat, diperoleh aplikasi } \\
\text { yang memiliki kelebihan yaitu tentang bagaimana memantau } \\
\text { perkembangan anak. }\end{array}$ \\
\hline
\end{tabular}

\section{PENDAHULUAN}

Menjadi ibu adalah fase yang sangat luar biasa dalam kehidupan seorang wanita. Selama sembilan bulan kita merangkai harapan serta doa untuk calon anak didalam kandungan[1]. Ketika bayi mungil itu hadir, kita tidak saja bahagia, tetapi menjadi begitu takjub dengan proses penciptaan dan kebesaranNya. Seorang ibu baru, seketika memiliki rasa keingintahuan dan perhatian yang begitu besar terhadap bayi mungilnya. Pengetahuan 
mengenai bagaimana merawat, mengasuh, dan membesarkan si kecil menjadi sebuah kebutuhan yang sangat penting bagi orang tua baru. Pengetahuan yang cukup membuatpara orang tua baru menjadi lebih percaya diri untuk menjalani peran barunya[2]. Dalam aplikasi ini memuat catatan-catatan persiapan kehamilan sampai kelahiran,informasi lengkap tentang ASI dan menyusui,Kesehatan, Imunisasi dan Solusi ketika si kecil sakit, Manajemen waktu bekerja dan mengurus anak dirumah, serta Tip dan Trik cerdas menjadi orang tua baru.

1. Pengertian Perancangan

Perancangan merupakan suatu aktivitas rekayasa perangkat lunak yang dikerjakan dengan mengunakan teknik yang bervariasi serta menyediakan rincian mengenai arsitektur dari perangkat lunak, struktur data, dan tampilan yang seringkali bersifat struktural[3]. Tujuan perancangan adalah menghasilkan model atau representasi entitas yang akan dibangun. Proses pembangunan model mengkombinasikan antara intuisi dan pertimbangan berdasarkan:

a. Pengalaman dalam membangun entitas-entitas serupa.

b. Sekumpulan prinsip dan/atau heuristik yang menuntun jalan dalam evolusi model.

c. Sekumpulan kriteria yang memungkinkan mempertimbangkan kualitas.

d. Proses iterasi yang menuntun ke representasi rancangan akhir.

2. Pengertian Aplikasi

Aplikasi merupakan suatu program yang siap untuk digunakan yang dibuat untuk melaksanakan suatu funsi bagi penguna jasa aplikasi serta bagi pengunaan aplikasi lain yang dapat digunakan oleh suatu sasaran yang akan dituju[4]

3. Pengertian Buku Pintar Ibu dan Bayi

Buku pintar ibu dan bayi merupakan sebuah buku yang berisi tentang Kehamilan dan pengasuhan anak sampai usia balita dari sudut pandang psikologi, dimana buku ini berguna bagi pengetahuan ibu dalam mengasuh bayi[5][6]. Selain dari sisi psikologis, buku pintar ibu dan bayi juga mencantumkan beberapa penjelasan medis, seperti angka kecukupan gizi untuk bayi, tabel imunisasi, dll. Ada juga ide kreatif seperti perencanaan babymoon, babyshoot, dsb[7].

4. Pengertian Android

Android adalah salah satu platform sistem operasi yang digemari masyakat karena sifatnya yang open source sehingga memungkinkan pengguna untuk melakukan pengembangan. Android merupakan generasi baru platform mobile berbasis linux yang mencakup sistem operasi, middleware, dan aplikasi[8].

\section{METODE}

Metode penelitian ini dirancang untuk digunakan sebagai kerangka acuan dan panduan tahapan penelitian. Dengan metode penelitian ini diharapkan proses penelitian dilakukan secara terarah dan sistematis. Penelitian ini bertujuan untuk membangun sistem dari awal. Untuk itu penelitian ini menggunakan metode pengembangan perangkat lunak waterfall, dimana hal ini menggambarkan pendekatan yang sistematis dan juga berurutan pada pengembangan perangkat lunak, dimulai dengan spesifikasi kebutuhan pengguna lalu berlanjut melalui tahapan-tahapan perencanaan (planning), permodelan (modeling), konstruksi (construction), serta penyerahan sistem ke para pelanggan/pengguna (deployment), yang diakhiri dengan dukungan pada perangkat lunak lengkap yang dihasilkan[9]. Langkah - langkah penelitian : 


\section{Analisa Kebutuhan}

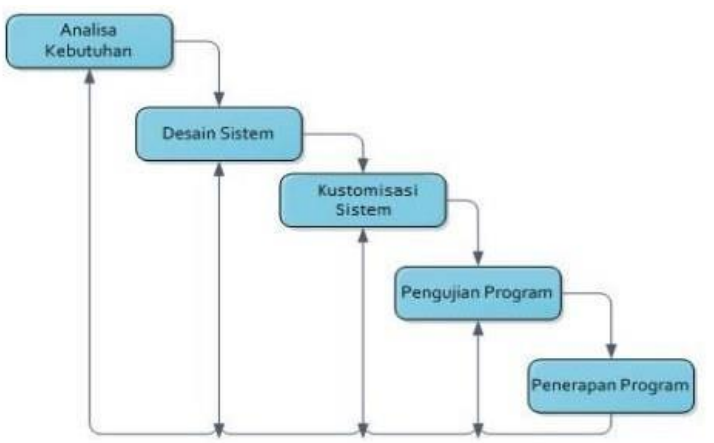

Gambar 1. Metode Pengembangan Sistem Waterfall

a. Pada tahap ini pengguna dan pengembang (peneliti) bersama-sama mendefinisikan format perangkat lunak secara menyeluruh, mengidentifikasikan semua kebutuhan terhadap fitur, dan garis besar sistem yang akan dibuat.

b. Pangguna yang akan diwawancara untuk mengidentifikasi kebutuhan adalah bidan, Ibu hamil, dan orang tua di KIA Puskesmas Janti Kecamatan Sukun Kota Malang.

1. Analisa Kebutuhan Input

Pada tahap ini pengguna pangguna yang akan diwawancara untuk mengidentifikasi kebutuhan adalah Bidan di Puskesmas Janti Kecamatan Sukun Kota malang. Bahan yang digunakan dalam penelitian ini adalah data primer yaitu data yang peroleh dari sumber bukubuku, jurnal, dan mengumpulkan informasi dari bidan desa dan studi literatur yang sejenis, kemudian dari data ini dapat disimpulkan mengenai kebutuhan atau persyaratan aplikasi yang akan dibuat. Sedangkan data yang lain diproleh melalui studi lapangan dan hal-hal yang menyediakan informasi tentang data terkait mengenai gizi dan nutrisi yang seimbang bagi ibu dan janinnya.

Sebelum melakukan pengumpulan data terlebih dahulu peneliti menemukan permasalahan yang akan diteliti mengenai aplikasi yang akan dibuat. Permasalahan yang muncul kebanyakan ibu-ibu malas untuk membaca buku mengenai kehamilan. Supaya tertarik dan minat untuk membaca, peneliti terinspirasi untuk membuat aplikasi berbasis android. Ibu-ibu akan lebih muda menggali informasi melalui android. Pengumpulan dan mengolah data yang menunjang pengembangan bahan pembuatan aplikasi.

2. Analisa Kebutuhan Perangkat

Pada proses pembuatan aplikasi ini, sistem membutuhkan beberapa perangkat lunak (software) dan perangkat keras (hardware). Berikut merupakan penjelasan dari perangkat lunak dan perangkat keras yang digunakan.

a. Perangkat Lunak yang Digunakan

Perangkat lunak yang digunakan untuk membangun sistem antara lain:

Operating System : Windows 10

Editor IDE

UML Modeler

: Android Studio

Image Editor

: Star UML

Development

: Corel Draw X7, Adobe Photoshop CS6 Android

: Android Development Kit 28

b. Perangkat Keras yang Digunakan

Sedangkan untuk perangkat keras yang digunakan diantaranya adalah:

Processor : : AMD Ryzen 5

Memory $\quad: 8.00 \mathrm{~GB}$

Pada tahapan testing aplikasi membutuhkan device android yang digunakan antara lain adalah :

Android version $\quad$ : Android API versi 23 keatas

Memory

: $2 \mathrm{~GB}$ 


\section{Desain Sistem}

Setelah dilakukan analisis kebutuhan, langkah selanjutnya adalah desain Perangkat lunak. Ada beberapa hal yang dilakukan dalam tahap desain pembuatan aplikasi Buku Pintar Ibu dan Anak. Yang pertama merupakan tampilan menu home, menu informasi kehamilan berisi tentang pilihan sub menu informasi kehamilan dan menu tentang berisikan informasi pembuat. Untuk menunjang keefektifan aplikasi Buku Pintar Ibu dan Bayi maka diperlukan Data Flow Diagram (DFD) sebagai langkah-langkah dalam proses pembuatan sebagai berikut:

a. Dfd Level 0

Dfd level 0 berisikan gambaran program keseluruhan, yang meliputi isi dari aplikasi Buku Pintar Ibu dan Bayi..

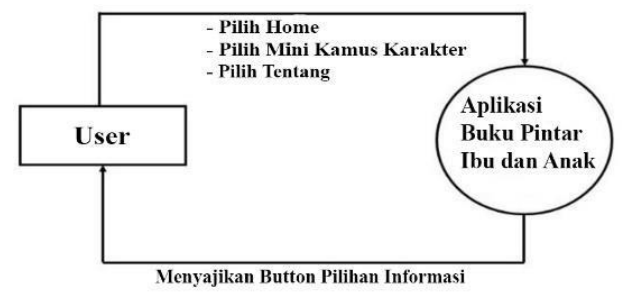

b. Dfd Level 1

Gambar 2. Dfd Level 0

Dfd level 1 berisi gambaran program pada tampilan pertama yang menampilkan button home, button informasi kehamilan dan button tentang, apabila user mengklik button home maka user akan dihadapkan dengan sapaan mengenai kamus menu. Sedangkan jika user memilih button mini kamus karakter maka akan tampil berbagai pilihan sub button yang tersedia. Apabila user memilih button tentang maka akan tampil identitas pembuat.

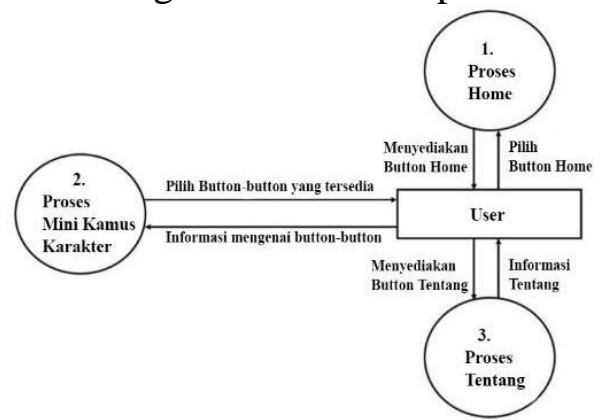

Gambar 3. Dfd Level 1

c. Dfd Level 2 Tampilan Muka

Dfd level 2 tampilan muka merupakan gambaran isi dari button home yang berisikan deskripsi mengenai menu.

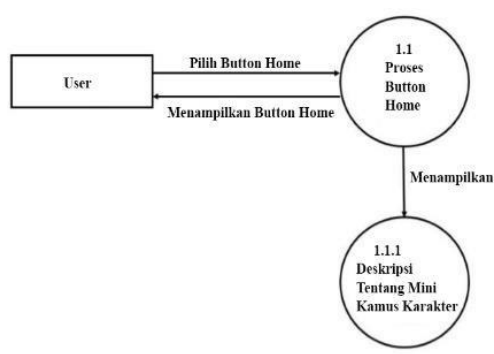

Gambar 4. Dfd Level 2

d. Dfd Level 3 Menu

Dfd level 3 Menu merupakan gambaran tampilan isi dari button Menu yang berisi tentang Mini Kamus Karakter, Familial Karakter, Personal Karakter dan Sosial Karakter 


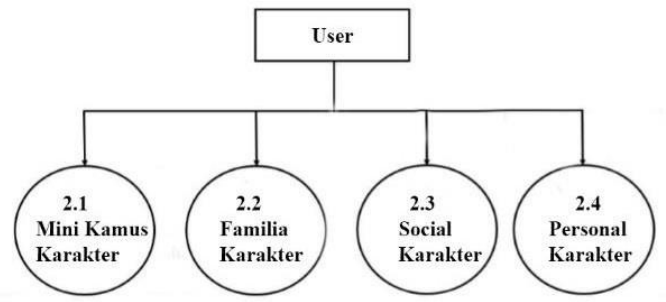

Gambar 5. Dfd Level 4

\section{HASIL DAN PEMBAHASAN}

\section{Perancangan antarmuka}

Perancangan antar muka atau tampilan aplikasi yang akan dibuat memberikan gambaran serta penjelasan pada setiap menu, teks, aktivitas dari sistem aplikasi. Desain antarmuka menjelaskan mengenai cara kerja aplikasi. Dalam pembuatan aplikasi BSBC (Bunda Sehat Bayi Cerdas) berbasis android, diperlikan desain antar muka sebagai gambaran terhadap aplikasi yang akan dibuat. Desain antarmuka akan ditampilkan peneliti sebagai berikut :

a. Tampilan Pertama Desain interface yang akan ditampilkan dapat dilihat pada gambar 6

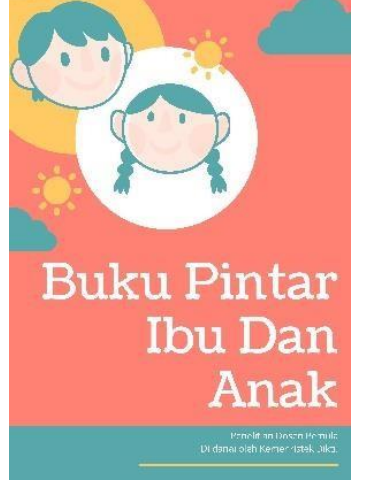

Gambar 6. Desain Interface

b. Tampilan isi Home Aplikasi Buku Pintar Ibu dan Anak. Pada tampilan Home menampilkan Menu pada Aplikasi Buku Pintar Ibu dan Anak, dapat dilihat pada gambar 7

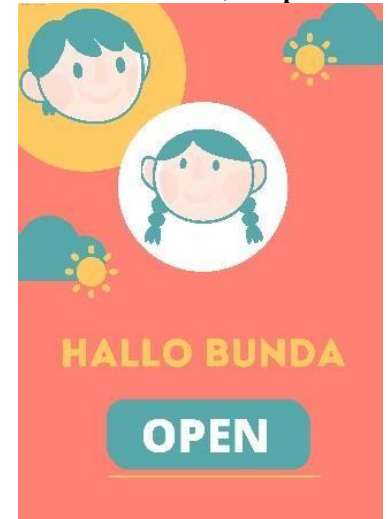

Gambar 7. Tampilan Isi

c. Tampilan Sub Menu Aplikasi Buku Pintar Ibu dan Anak. Pada tampilan Sub Menu menampilkan beberapa Sub menu yang dapat dipilih. Seperti Kamus Mini Karakter, familia karakter, social karakter, dan personal karakter. Dapat dilihat pada gambar 8 


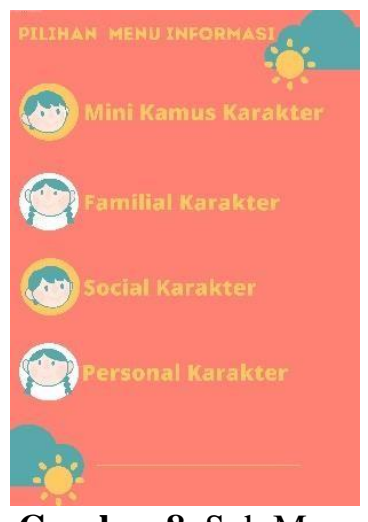

Gambar 8. Sub Menu

d. Tampilan Isi Aplikasi Buku Pintar Ibu dan Anak. Pada tampilan ini, setelah kita memilih salah satu sub menu, kemudian akan muncul isi pada Aplikasi Buku Pintar Ibu dan Anak. Dapat dilihat pada gambar 9

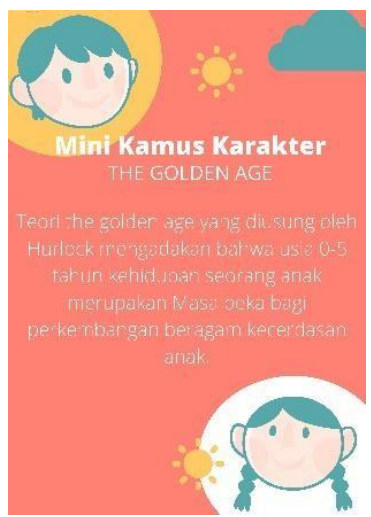

2. Pengujian

Gambar 9. Tampilan Isi Aplikasi

Pengujian sistem pembuatan aplikasi Buku Pintar Ibu dan Bayi (Bunda Sehat Bayi Cerdas) di Puskesmas Janti Kecamatan Sukun Kota Malang dengan menggunakan kuesioner secara langsung. Hasil dari kuesioner tersebut terdiri dari satu validitas yaitu 15 pengguna. Kriteria dalam penentuan subyek pengguna yaitu ibu hamil, bidan dan kader posyandu. Validitas tersebut didapatkan hasil penilaian oleh pengguna 15 orang berdasarkan data ibu hamil di KIA Puskesmas Janti Kecamatan Sukun Kota Malang

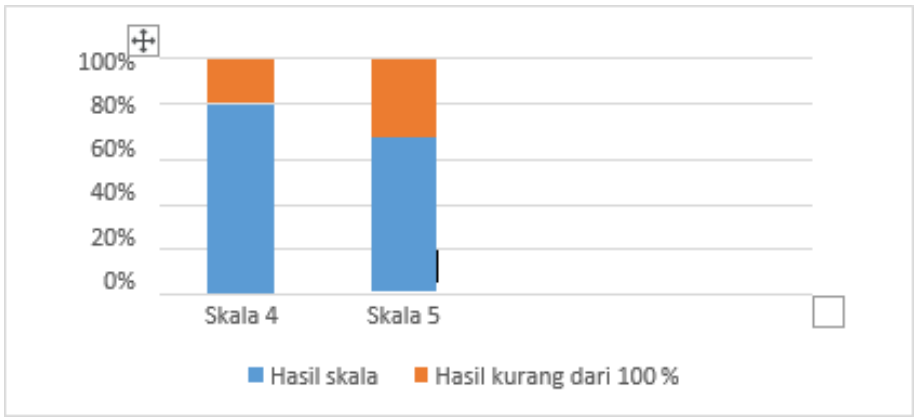

Gambar 10. Penilaian Hasil Pengguna

Pada gambar 10 berisi rekapitulasi hasil pengujian usability yang telah dikelompokkan berdasarkan skala hasil skor yang diperoleh. Penghitungan skor yang diperoleh dari masingmasing pertanyaan adalah sebagai berikut:

Skala $4=4 \times 80=320$

Skala $5=5 \times 70=350$

Jumlah $=670$ Jumlah Data $(n)=15$

Jumlah Pertanyaan $=10$

Data Tertinggi $(\mathrm{MAX})=5 \times 10 \times 15=750$

Data Terendah $(\mathrm{MIN})=4 \times 10 \times 15=600$

Persentase Kelayakan $=$ Indeks $\%=($ Total Skor $/$ Skor Maksimum $) \times$ 
$100600 / 750 \times 100 \%=89,3 \%$

Berdasarkan hasil perhitungan di atas, penilaian tentang penyesuaian interpretasi skala Likert. Hasil skor yang didapatkan adalah 89,3\%. Berdasarkan kriteria pada gambar 11 kelayakan[5], total skor tersebut termasuk dalam kategori sangat layak.

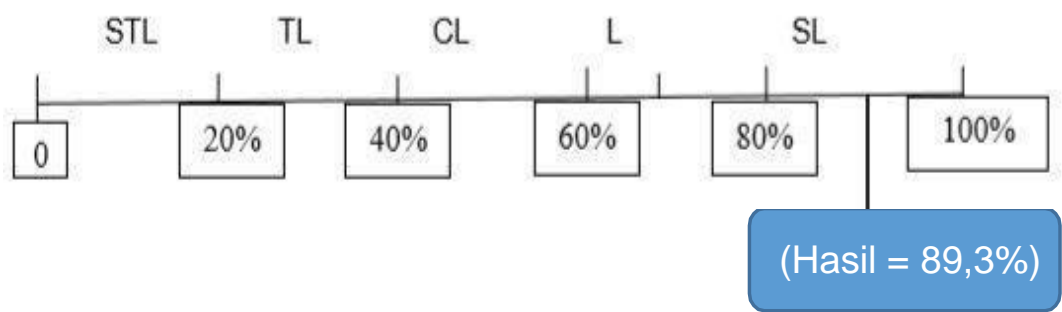

Keterangan :

Gambar 11. Skala Kategori Kelayakan Hasil Uji Coba Dari Ahli Materi

Pada skala 0 sampai $20 \%$ menghasilkan presentase STL = Sangat tidak layak. Pada skala 20\% sampai $40 \%$ menghasilkan presentase TL = Tidak Layak. Pada skala $40 \%$ sampai $60 \%$ menghasilkan presentase $\mathrm{CL}=$ Cukup Layak. Pada skala $60 \%$ sampai $80 \%$ menghasilkan presentase L = Layak. Pada skala $80 \%$ sampai $100 \%$ menghasilkan presentase SL = Sangat layak

\section{SIMPULAN DAN SARAN} berikut :

Berdasarkan pada hasil penelitian dan pembahasan, maka dapat disimpulkan sebagai

1. Pembuatan aplikasi Buku Pintar Ibu dan Bayi Android Studio. Metode penelitian menggunakan metode waterfall. Proses pembuatan aplikasi ini melalui tahap, yaitu mengenai pembuatan $\mathrm{dfd}$, usecase diagram, activity diagram, flowchart perancangan program, dan perancangan antarmuka atau user interface. Sebelum dilakukan uji coba aplikasi.

2. Kelayakan aplikasi Buku Pintar Ibu dan Anak dapat dikategorikan aplikasi "layak" sehingga aplikasi ini dapat digunakan untuk ibu hamil dan pihak KIA Puskesmas Janti Kecamatan Sukun Kota Malang. Dapat dilihat dari hasil pengujian yaitu:

a. Berdasarkan uji coba lapangan oleh ibu hamil, media pembelajaran ini memperoleh nilai $89,3 \%$ sehingga Sangat layak untuk dijadikan media informasi pendamping dalam ibu hamil dan mengasuh anak.

b. Berdasarkan hasil penelitian yang diperoleh, maka saran yang diberikan peneliti adalah dapat ditambahkan menu komentar, agar pengguna dapat saling bertukar pendapat dengan pengguna lain atau admin, dapat ditambahkan pemberitahuan jika halaman dapat di scroll, serta isi kontennya dapat diperbaharui lagi.

\section{DAFTAR PUSTAKA}

[1] S. Nurhidayah, "Kelekatan (Attachment) dan Pembentukan Karakter," J. FAI TURATS, vol. 7, no. 2, 2011.

[2] A. S. Fatimaningrum, "KAJIAN PSIKOLOGIS DALAM PEMILIHAN PERMAINAN KREATIF YANG MERANGSANG PERKEMBANGAN ANAK USIA DINI," Yogyakarta, 2008.

[3] R. S. Pressman, Rekayasa Perangkat Lunak. Andi, 2010.

[4] Hendrayudi, VB 2008 untuk berbagai keperluan Pemrograman. Jakarta: Media Komputindo, 2009.

[5] A. B. Nirwana, Ibu, Bayi dan Anak. Yogyakarta: Nuhamedika, 2011.

[6] A. Woolfolk, Educational Psychology, 5th Editio. United States of America, 1989.

[7] N. Nurdiansyah, Buku Pintar Ibu dan Bayi. Bukuné, 2011.

[8] H. Supriyono, A. Nur Saputra, E. Sudarmilah, and R. Darsono, "Rancang bangun aplikasi pembelajaran hadis untuk perangkat mobile berbasis Android," J. Inform., vol. 8, no. 2, pp. $907-$ 920, 2014.

[9] Arikunto, Prosedur Penelitian, Suatu Pendekatan Praktek. Jakarta: Rineka Cipta, 2009. 